Effects of Shinrin-Yoku Retreat on Mental Health: A Pilot Study in Fukushima, Japan Yasuhiro Kotera $^{1 *}$, Dean Fido ${ }^{2}$

${ }^{1}$ Human Sciences Research Centre, University of Derby, Derby, United Kingdom

${ }^{2}$ Department of Criminology, University of Derby, Derby, United Kingdom

*Corresponding author: Y.Kotera@derby.ac.uk / +44(0)1332 592670 / University of Derby, Derby, Derbyshire, Kedleston Road, DE22 1GB, United Kingdom.

https://www.tandfonline.com/toc/rhpr20/current

https://onlinelibrary.wiley.com/page/journal/17480361/homepage/forauthors.html 


\section{Effects of Shinrin-yoku Retreat on Mental Health: A Pilot Study in Fukushima, Japan}

\section{Abstract (200)}

Shinrin-yoku (forest bathing) is a cost-effective healing practice, and has attracted the interest of scientists. Recently, its effects on mental health has been increasingly reported. Japanese university students suffer from high rates of mental health problems, and the number of suicides remain high, despite the total number of suicides in Japan has been decreasing. Effective mental health approaches are sought after for Japanese students, however healthful treatment has not been identified to date. Accordingly, this pre-post pilot study evaluated the levels of mental wellbeing, self-compassion, and loneliness among 25 Japanese undergraduate students who participated in a three-day shinrin-yoku retreat in Fukushima, before, straight after and two weeks after the retreat. The mean scores of mental wellbeing increased significantly from pre-retreat to post-retreat; self-compassion and common humanity increased significantly from pre-retreat to follow-up; and mindfulness increased significantly from pre-retreat to post-retreat, and from pre-retreat to follow-up. The mean scores of loneliness did not make any significant changes. As self-compassion has been found strongly associated with mental health of university students, shinrin-yoku retreat should be evaluated with a larger sample and in a shorter time frame.

Keywords: shinrin-yoku; mental health; mental wellbeing; self-compassion; loneliness;

\section{Fukushima}

Acknowledgement: We thank Mr Masayuki Yamanaka, who organised this retreat, and his students, and resilient people in Fukushima who kindly supported this retreat. 


\section{Introduction}

The use of nature to increase or maintain key facets of physical and mental wellbeing is a well-established movement in psychological investigation, and has informed the basis of governmental policy in some countries (Department for Environment, Food and Rural Affairs (DEFRA), 2018). Specifically, nature has been implicated in improved levels of anxiety, happiness, life satisfaction, and resilience (Martyn \& Brymer, 2016; Pritchard, Richardson, Sheffield, \& McEwan, 2019; Ryan et al., 2010), and is considered beneficial for cognitive functioning (Caccioppo \& Hawkley, 2009) and empathy towards others (Fido \& Richardson, 2019).

In Japanese culture, the relationship between nature and wellbeing has also been embedded in clinical practice, with one such example being shinrin-yoku (‘森林浴’); a term created in 1982 by the Japanese Ministry of Agriculture, Forestry, and Fisheries, and which roughly maps onto the concept of forest bathing in English literature. At its core, shinrin-yoku is the process of relaxing, taking long deep breaths, and observing (through sight, sound, smell, and touch) ones' nature-based surroundings (Miyazaki, 2018). Although a relatively new concept in most countries (Rajoo et al., 2019), the physical benefits of shinrin-yoku are well documented. Being surrounded by nature for sustained periods of time has been associated with improvement in one's immune system, as well as cardiovascular and respiratory functioning (Jung, Woo, \& Ryu, 2015; Williams, 2016). As such, shinrin-yoku has proven popular in the East (Yu \& Hsieh, 2020), potentially as a function of its ease in implementation, and cost- and resource-efficient nature (Kotera \& Rhodes, 2020).

What's more is that seemingly there is converging evidence to suggest that engagement in shinrin-yoku leads to benefit in psychological wellbeing as well. Shinrin-yoku has been shown to be effective for reducing a host of psychologically-relevant indices, 
including depression, anxiety, anger, selfishness, and stress (Kotera, Richardson, \& Sheffield, 2020; Park, Tsunetsugu, Lee, Kagawa, \& Miyazaki, 2012; Pritchard et al., 2019). Moreover, a three-day shinrin-yoku intervention reportedly led to significantly reduced scores on dimensions of tension-anxiety, anger-hostility, depression-dejection, as well as confusion-bewilderment within a Profile of Mood States (Yu \& Hsieh, 2020). Given that poor mental health (and the presence of mental health disorders) represents a global issue (thought to affect around 1.1 billion people (Ritchie \& Roser, 2018)), and contribute to economic output losses of \$2.5-8.5 trillion (Patel et al., 2018), finding resource- and cost-efficient means of alleviating related symptoms holds importance.

Mental health is currently one of the top national agendas in Japan (Miyake \& Okamoto, 2015) as the rates of depressive and anxiety disorders are second highest in the world, counting five million and three million cases respectively (Ratanasiripong, China, \& Toyama, 2018). Japan has the highest rate of suicides in developed countries, and $41 \%$ of suicides are understood to be caused by mental distress (National Police Agent, 2010). More concerningly, the rates of mental distress (depression and anxiety diagnoses) are on the increase in recent years (Ministry of Health Labour and Welfare (MHLW), 2017). Although some scholars suggest that this increase might be a result of increased access to and use of mental health services (Nishi, Ishikawa, \& Kawakami, 2019), the fact that more than 20,000 people have completed suicide each year since 1998 (MHLW, 2020) — of which 30,000 people have completed suicide each year from 1998 to 2011 (Shiiba, 2013) - further compounds why we should care about this population. Specifically, Japanese university students are of particular risk despite an increased access to and engagement with institutional mental health services (Adachi et al., 2020). Poor student mental health not only leads to detriment in academia, such as lower grades and increased absences (Hunt \& 
Eisenberg, 2010), but has graver impact, with about 1000 Japanese university students complete suicide every year (while suicides in other populations and the total in Japan have been decreasing), making it the most frequent cause of death in this population (MHLW, 2020; Uchida, 2010).

Comorbid with the presence of poor mental health is a lack of self-compassion and increased loneliness. Self-compassion refers to the generation of positive self-attitudes towards oneself and the ability to understand one's own experiences in an un-biased and driven fashion, and has been associated with blunting the impact of negative experiences (Neff, 2013), increased psychological well-being (Zessin et al., 2015), and preventing the onset of anxiety and depression (MacBeth \& Gumley, 2012; Van Dam et al., 2011). One potential mechanism for this is self-compassion acting on perceived stress; as was found in a mediation study within Chinese nursing students (Luo et al., 2019). Although compassion has been identified as one of the five pathways to connecting oneself with nature (Lumber, Richardson, \& Sheffield, 2017), to our knowledge, there exists no evidence outlining the impact of shinrin-yoku on self-compassion, specifically. Similarly, loneliness is a key predictor of poor mental health (Cacioppo et al., 2015). In younger people (such as students) such relationships might partially manifest through a disparity between expected and perceived qualities of social relationships (Peplau \& Perlman, 1982); thus accounting for why university students might experience loneliness even though they are surrounded by, and often live with, peers (Richardson, Elliott, \& Roberts, 2017). Although experiences of nature are hypothesised to reduce experiences of loneliness (WHO, 2017)—with such associations explicitly featured in Governmental policy (DEFRA, 2018), as with self-compassion-it remains unknown whether shinrin-yoku specifically impacts experiences of loneliness. 
As such, this manuscript reports on a pre-post three-day shinrin-yoku intervention study with specific focus on three mental health outcomes; that of general mental wellbeing, self-compassion, and loneliness. Based on the literature document above, we hypothesised that following intervention, general mental well-being and self-compassion would be increased, and loneliness would be reduced. Comparisons are also explored with two-week follow-up measures to explore lasting efficacy of the intervention.

\section{Methods}

\section{Participants}

Participation in this study had to be aged 18 or older, enrolled in an undergraduate programme at a Japanese university in Tokyo, and without any diagnosed mental disorders. Of 28 undergraduate students who consented to participate, 25 (15 males and 10 females, Age $20.40 \pm 2.60$, Range 18-28 years old) completed all three assessments (pre, post, and follow-up). Nine of them were first year students, eight were second year students, five were third year students, and three were fourth year students.

\section{Materials}

The three scales (mental wellbeing, self-compassion, and loneliness) were responded to at three time points: before, straight after, and two weeks after the retreat.

Mental wellbeing was measured using the Warwick-Edinburgh Mental Wellbeing Scale (WEMWBS), a 14-item self-report measure on a five-point Likert scale ( 1 = 'None of the time' to 5 = 'All the time'; Stewart-Brown et al., 2009). Participants were asked to reflect on the past two weeks to respond to items such as 'I've been feeling optimistic about the future'. The 14 items cover three categories of mental wellbeing - one's psychological 
functioning, satisfaction from life, and ability to nurture reciprocal relationships (Stewart-Brown \& Janmohamed, 2008). Internal consistency of WEMWBS was high $(\alpha=$ .89-.91; Tennant et al., 2007).

Self-compassion Scale (SCS; Neff, 2003) was used to measure self-compassion, a 26-item scale on a five-point Likert scale (1='Almost never' to 5='Almost always'). The 26 items in SCS are divided into six subscales relating to three positive constructs and three negative constructs. The positive constructs are self-kindness (five items; e.g., 'I try to be loving towards myself when I'm feeling emotional pain'), common humanity (four items; e.g., 'When things are going badly for me, I see the difficulties as part of life that everyone goes through.'), and mindfulness (four items; e.g., 'When something upsets me, I try to keep my emotions in balance'), whereas the negative constructs are self-judgement (five items; e.g., 'I'm disapproving and judgmental about my own flaws and inadequacies'), isolation (four items; e.g., 'When I think about my inadequacies, it tends to make me feel more separate and cut off from the rest of the world'), and over-identification (four items; e.g., 'When I'm feeling down I tend to obsess and fixate on everything that's wrong'). Each subscale is calculated by summing the responses, however the total score of self-compassion is calculated by reversing the negative constructs. Internal consistencies of SCS were high; $\alpha$ $=.92$ for the total self-compassion scale, and $\alpha=.75-.81$ for each subscale (Neff, 2003).

Lastly, the University of California Los Angeles Loneliness Scale (UCLA-LS) version 3 was used to measure loneliness (Russell, 1996). This 20-item scale on a four-point Likert scale ( $0=$ 'I never feel this way' to $3=$ 'I often feel this way') asks how often each statement applies to you (e.g., 'I am unhappy doing so many things alone'), and all responses are added to calculate the level of loneliness. LS had a good internal consistency $(\alpha=.89-.94$; Russell, 1996). 


\section{Procedure}

Once the consent has been made, participants responded to WEMWBS, SCS, and UCLA-LS, then attended a three-day shinrin-yoku retreat in a forest in Fukushima, Japan, facilitated by a trainer who had more than ten years of experience in nature-assisted therapy and supporting student well-being. Straight after the retreat, and two weeks after the retreat, participants responded to the same three scales. All scales were prepared online, and the links were sent to participants at each assessment point.

Fukushima was chosen for this retreat because of its rich and diverse nature. While aiming to support students' wellbeing, this retreat was hoped to inform the recovery of Fukushima from the 2011 Tohoku Earthquake and Tsunami, and the Fukushima Daiichi Nuclear Disaster, where in total more than 19,000 people ceased (Ministry of Internal Affairs and Communication, 2016).

Shinrin-yoku retreat consisted of an arrival at, and a walk around the area (Day 1), water activities such as paddle boarding (Day 2), and earth activities such as harvesting vegetables (Day 3). Each day, participants were engaged in 30 minutes of meditation and 30 minutes of yoga in a group in order to bring their four-sensory experience (sight, sound, smell, and touch) to awareness. Ethical approval was granted from the university research ethics committee.

\section{Statistical Analysis}

SPSS version 25 was used for data analysis. A one-way repeated measures analysis of variance (ANOVA), once outliers were examined. To assess differences among the three assessment points, post-hoc Tukey analyses were conducted. No scores were identified as 
outliers using the outlier labelling rule (Hoaglin \& Iglewicz 1987). Assumption of normality was of no concern as a one-way ANOVA was accurate with non-normally distributed data (Plichta \& Garzon, 2009). The reliable change criteria (RCC) were calculated by multiplying the standard error of change by 1.96: SD $\times \sqrt{ } 2 \times \sqrt{ }(1-\alpha) \times 1.96$ (Christensen $\&$ Mendoza, 1986).

\section{Results}

RCC for each variable were calculated: 9.45 for mental well-being, .57 for self-compassion, 1.07 for self-kindness, 1.21 for self-judgement, 1.37 for common humanity, 1.11 for isolation, 1.33 for mindfulness, 1.14 for over-identification, and 10.74 for loneliness. For all variables, there was homogeneity of variances, as assessed by Levene's test for equality of variances $(p \geqq .40)$. Because all scores apart from self-kindness and loneliness were not normally distributed (Shapiro-Wilk $p>.05$ ), data were square-root-transformed.

Table 1. Descriptive statistics and a one-way repeated measures ANOVA for the effects of nature retreat on mental wellbeing, self-compassion, and loneliness among Japanese students $(n=25)$.

\begin{tabular}{|r|c|c|c|c|c|c|c|c|c|}
\hline & \multicolumn{3}{|c|}{ Pre-Retreat } & \multicolumn{3}{c}{ Post-Retreat } & \multicolumn{3}{c|}{ Follow-up } \\
\cline { 2 - 11 } & M & SD & $\alpha$ & M & SD & $\alpha$ & M & SD & $\alpha$ \\
\hline Mental Wellbeing & $48.20^{\mathrm{e}}$ & 9.11 & .86 & $55.00^{\mathrm{e}}$ & 9.90 & .92 & 53.16 & 11.68 & .95 \\
\hline Self-Compassion* & $2.84^{\mathrm{a}}$ & .69 & .91 & 3.14 & .65 & .91 & $3.34^{\mathrm{a}}$ & .64 & .92 \\
\hline Self-Kindness & 2.99 & .77 & .75 & 3.23 & .95 & .88 & 3.31 & .93 & .90 \\
\hline Self-Judgement & 3.34 & 1.03 & .82 & 3.18 & 1.06 & .91 & 3.05 & .90 & .88 \\
\hline Common Humanity* & $2.93^{\mathrm{b}}$ & .81 & .63 & 3.38 & .86 & .69 & $3.62^{\mathrm{b}}$ & .92 & .82 \\
\hline Isolation & 3.27 & 1.07 & .86 & 2.94 & .91 & .74 & 2.54 & .99 & .82 \\
\hline Mindfulness* & $2.98^{\mathrm{cd}}$ & .75 & .59 & $3.45^{\mathrm{c}}$ & .71 & .55 & $3.67^{\mathrm{d}}$ & .67 & .63 \\
\hline Over-Identification & 3.33 & 1.14 & .87 & 3.11 & .97 & .81 & 2.97 & .88 & .74 \\
\hline Loneliness & 52.36 & 6.96 & .69 & 49.92 & 7.18 & .71 & 49.38 & 7.04 & .71 \\
\hline
\end{tabular}

${ }^{*} p<.05$. Superscripts ${ }^{(-\mathrm{a})}$ indicate there was a significant difference between the two. 
A one-way repeated measures ANOVA was conducted. Total score of self-compassion, and its subscales, common humanity and mindfulness changed statistically significantly between different assessment points (Self-compassion $\mathrm{F}(2,74)=3.77, p=.03, \omega^{2}=.0004$; Common humanity $\mathrm{F}=3.80, p=.03, \omega^{2}=.0003$; Mindfulness $\left.\mathrm{F}=6.36, p=.003, \omega^{2}=.00005\right)$. No significant changes were not observed in mental wellbeing and loneliness.

The means of self-compassion, common humanity, and mindfulness increased from pre-retreat (Self-compassion 2.84 \pm .69 ; Common humanity $2.93 \pm .81$; Mindfulness $2.98 \pm$ .75 ) to post-retreat (Self-compassion $3.14 \pm .65$; Common humanity $3.38 \pm .86$; Mindfulness $3.45 \pm .71$ ), and increased at follow-up (Self-compassion $3.34 \pm .64$; Common humanity 3.62 \pm .92 ; Mindfulness $3.67 \pm .67$ ). Tukey post-hoc analyses revealed that i) the significant mean increases were yielded from pre-retreat to follow-up in all the three variables (Self-compassion $p=.02$; Common humanity $p=.02$; Mindfulness $p=.002$ ), ii) the only significant mean increase from pre-retreat to post-retreat was yielded in mindfulness $(p=$ .048), and iii) there was no significant mean difference from post-retreat to follow-up in any variable.

As mental wellbeing did not change between different assessment points, Games-Howell post hoc analyses were conducted to explore whether there were any significant mean differences. Mental wellbeing changed significantly between pre-retreat and post-retreat (increased from pre-retreat to post-retreat $p=.04$ ).

Lastly, based on the RCC, the ratio and number of participants who have made reliable changes in each variable were calculated (Table 2). In line with our findings above, relatively many participants experienced reliable changes in mental wellbeing, self-compassion, common humanity, and mindfulness. 
Table 2. The ratio and number of participants who have made reliable changes in each variable.

\begin{tabular}{|r|c|c|c|c|}
\hline & RCC & Pre-Post & Pre-Follow-up & Post-Follow-up \\
\hline Mental Wellbeing & 9.45 & $32 \%(8)$ & $32 \%(8)$ & $0 \%(0)$ \\
\hline Self-Compassion & .57 & $20 \%(5)$ & $36 \%(9)$ & $24 \%(6)$ \\
\hline Self-Kindness & 1.07 & $16 \%(4)$ & $16 \%(4)$ & $4 \%(1)$ \\
\hline Self-Judgement & 1.21 & $16 \%(4)$ & $16 \%(4)$ & $4 \%(1)$ \\
\hline Common Humanity & 1.37 & $24 \%(6)$ & $24 \%(6)$ & $4 \%(1)$ \\
\hline Isolation & 1.11 & $20 \%(5)$ & $8 \%(2)$ & $16 \%(4)$ \\
\hline Mindfulness & 1.33 & $20 \%(5)$ & $28 \%(7)$ & $28 \%(7)$ \\
\hline Over-Identification & 1.14 & $12 \%(3)$ & $16 \%(4)$ & $16 \%(4)$ \\
\hline Loneliness & 10.74 & $12 \%(3)$ & $20 \%(5)$ & $16 \%(4)$ \\
\hline
\end{tabular}

$\mathrm{RCC}=$ Reliable Change Criteria

\section{Discussion}

This manuscript assessed whether the outcome variables of general mental wellbeing, self-compassion, and loneliness would improve following a three-day shinrin-yoku (forest bathing) retreat in rural Fukushima, Japan (and subsequent two-week follow-up), which involved a forest walk, water activities, harvesting, meditation, and yoga. As predicted, self-reported indices of self-compassion, common humanity, and mindfulness increased between pre- and post-retreat, and were sustained at two-week follow up. Moreover, mental wellbeing increased between pre- and post-retreat, however there were no significant differences in scores of loneliness.

Previous investigations have suggested that engagement in shinrin-yoku might bring about positive change in psychologically-relevant outcomes such as depression, anxiety, and stress (Kotera et al., 2020; Pritchard et al., 2019), even after interventions of similar length to 
ours (Yu \& Hsieh, 2020). As such, it is unsurprising to see that in our sample, self-reported measures of general mental wellbeing increased between pre- and post-retreat time points. Unexpectedly, there was not strong evidence within our dataset to suggest that increases in mental wellbeing were sustained after the two-week follow up - although importantly, descriptive-level data did not indicate that the average means returned to baseline. Combined with the fact that the WEMWBS (Stewart-Brown et al., 20무) does not distinguish between specific dimensions of mental wellbeing, and previous literature has shown individual variation between facets of (for example) depression, anxiety, and stress (Fido, Kotera, \& Asano, 2019), it remains to be seen whether shinrin-yoku might individually act upon these dimensions. Given the increased incidence of poor mental health (MHLW, 2015) and related suicidal behaviour (Shiiba, 2013) in Japan over the last twenty years, these findings represent a potential avenue of treatment (or an accompaniment to treatment).

Our data also evidenced a sustained increase in self-compassion, and two of its sub-facets; common humanity and mindfulness. Self-compassion is considered a predictor of psychological well-being (Kotera \& Ting, 2019; Zessin et al., 2015), and heightened reports of self-compassions have been associated with the prevention of the onset of anxiety and depression (MacBeth \& Gumley, 2012; Van Dam et al., 2011). In our introduction, we document the absence of any existing literature pertaining to the role of nature and self-compassion specifically, however, as Lumber et al. (2017) highlight that our connection with nature can be achieved through compassion (alongside contact, emotion, meaning, and beauty), results here are not unexpected. Given that self-compassion might be considered to act as a protector from negative experiences and poor mental wellbeing (Neff, 2013), future research should explore this as a potential mechanism by which shinrin-yoku acts on mental wellbeing; as was shown in another Eastern student cohort (Luo et al., 2019). 
Surprisingly, our data suggests that engagement in shinrin-yoku did not bring about any significant changes in self-reported levels of loneliness. Loneliness has been described as a core predictor of poor mental health (Cacioppo et al., 2015); including suicidal ideation and associated behaviour via the mechanism of contributing to depression (McClelland et al., 2020). In student populations, such as ours, loneliness may be operationalised through poor quality social relationships that conceptually differ from what they expect (Peplau \& Perlman, 1982; Richardson, Elliott, \& Roberts, 2017). As such, one might hypothesise that shinrin-yoku moderates the more internal aspects of mental wellbeing, and not preserve the negative outcomes associated with the social elements which contribute to mental health. Such findings also go some way to placing caveats on claims by the World Health Organization (2017) that experiences of nature can reduce the experiences of loneliness. However, of importance, this study did not measure changes in experiences of nature connectedness; the underlying trait that encapsulates the cognitive and affective construction of ones' interconnectedness with the natural world (Capaldi, Dopko, \& Zelenski, 2014); a potential conduit of the effect of shinrin-yoku.

\section{Limitations and future research}

Limitations and future research are discussed below. First, data was self-reported and as such may be subject to response biases (Kotera, Van Laethem, \& Ohshima, 2020). Recently, personality researchers (e.g., Harper et al., 2020) have urged for the use of other-reported data when exploring changes in behaviour and mental-health related outcome variables which are closely associated with behaviour as a means of mitigating this limitation. Second, and entwined with the first limitation, is that although a positive change was identified for core outcome variables, the questionnaire scales used are not suitable to 
measure clinically-meaningful levels of said variables, and so the clinical relevance of shinrin-yoku remains to be understood. Furthermore, although SCS is commonly used to measure the level of self-compassion, its accuracy has been debated (e.g., Lopez et al., 2013). Nevertheless, these preliminary results are positive and provide concrete grounding for future intervention work with clinical groups. Finally, the shinrin-yoku intervention comprised several unique sessions, and so even though the retreat as a whole can claim to positively impact the wellbeing of those who take part, the specific mechanism underpinning this change requires more thorough exploration.

\section{Conclusion}

Taken together, our data show that engaging in a shinrin-yoku retreat over a three-day period can bring about (mostly) prolonged benefit for self-compassion and mental wellbeing among Japanese university students, who suffer from high rates of mental health problems. Although several limitations have been highlighted throughout, which all warrant more detailed examinations of the mechanisms by which shinrin-yoku modulates the aforementioned outcome variables, data reported here presents an encouraging first step for bringing about meaningful change. As mental health represents a global issue with severe financial and wellbeing implications (Patel et al., 2018; Ritchie \& Roser, 2018), with disproportionate impact on students (Cabinet Office, 2012; Hunt \& Eisenberg, 2010), shinrin-yoku might represent a resource- and cost-efficient intervention, which could accompany pre-existing medications and treatment programmes. Going forward, pressure-testing the duration of such retreats documented here is essential to better understand the optimum amount of time required to bring about clinically-meaningful change. 
Authors declare no conflict of interest.

\section{References}

Adachi, H., Yamamura, A., Nakamura-Taira, N., Tanimukai, H., Fujino, R., Kudo, T., \& Hirai, K. (2020). Factors that influence psychiatric help-seeking behavior in Japanese university students. Asian Journal of Psychiatry, 51, 102058.

Ashworth, M., 2019. How Does Stress Affect Us? Retrieved from. https://psychcentral.com/lib/how-does-stress-affect-us/.

Cacioppo, J. T., \& Hawkley, L. C. (2009). Perceived social isolation and cognition. Trends in Cognitive Science, 13(10), 447-454.

Cacioppo, S., Grippo, A. J., London, S., Goossens, L., \& Cacioppo, J. T. (2015). Loneliness: Clinical import and interventions. Perspectives on Psychological Science, 10(2), $238-249$.

DEFRA. (2018). A Green Future: Our 25 Year Plan to Improve the Environment. DEFRA: London, UK.

Fido, D., Kotera, Y. \& Asano, K. (2019). English Translation and Validation of the Ikigai-9 in a UK Sample. International Journal of Mental Health and Addiction, [online first].

Fido, D., \& Richardson, M. (2019). Empathy Mediates the Relationship Between Nature Connectedness and Both Callous and Uncaring Traits. Ecopsychology, 11(2).

Harper, C. A., Satchell, L. P., Fido, D., \& Latzman, R. D. (2020). Functional Fear Predicts Public Health Compliance in the COVID-19 Pandemic. International Journal of Mental Health and Addiction, [online first].

Hunt, J., Eisenberg, D., 2010. Mental health problems and help-seeking behavior among college students. Journal of Adolescent Health, 46, 3-10. 
Jung, W. H., Woo, J. M., \& Ryu, J. S. (2015). Effect of a forest therapy program and the forest environment on female workers' stress. Urban Forestry \& Urban Greening, 14(2), 274-281.

Kotera, Y., \& Ting, S.-H. (2019). Positive psychology of Malaysian university students: Impacts of engagement, motivation, self-compassion, and well-being on mental health. International Journal of Mental Health and Addiction. https://doi.org/10.1007/s11469-019-00169-z

Kotera, Y., Van Laethem, M., \& Ohshima, R. (2020). Cross-cultural comparison of mental health between Japanese and Dutch workers: relationships with mental health shame, self-compassion, work engagement and motivation. Cross Cultural and Strategic Management. https://doi.org/10.1108/CCSM-02-2020-0055

Kotera, Y., Richardson, M. \& Sheffield, D. (2020). Effects of Shinrin-Yoku (Forest Bathing) and Nature Therapy on Mental Health: a Systematic Review and Meta-analysis. International Journal of Mental Health and Addiction. [online first] https://doi.org/10.1007/s11469-020-00363-4

López, A., Sanderman, R., Smink, A., Zhang, Y., van Sonderen, E., Ranchor, A., \& Schroevers, M. J. (2015). A reconsideration of the Self-Compassion Scale's total score: Self-compassion versus self-criticism. PLOS ONE, 10(7), e0132940. https://doi.org/10.1371/journal.pone.0132940

Luo, Y., Meng, R., Li, J., Liu, B., Cao, X., \& Ge, W. (2019). Self-compassion may reduce anxiety and depression in nursing students: a pathway through perceived stress. Public Health, 174, 1-10, 
MacBeth A, \& Gumley A. (2012). Exploring compassion: a meta-analysis of the association between self-compassion and psychopathology. Clinical Psychology Review, 32, $545-552$.

Martyn, P., \& Brymer, E. (2016). The relationship between nature relatedness and anxiety. Journal of Health Psychology, 21(7), 1436-1445

McClelland, H., Evans, J. J., Nowland, R., Ferguson, E., O'Connor, R. C. (2020). Loneliness as a predictor of suicidal ideation and behaviour: a systematic review and meta-analysis of prospective studies. Journal of Affective Disorders, 274, 880-896,

Ministry of Health Labour and Welfare. (2017). Patients survey [Kanja chousa]. Tokyo: Author.

Ministry of Health Labour and Welfare. (2020). Suicides during the first year of Reiwa, 2019 [Reiwa gannenn chu niokeru jisatsu no joukyou]. Tokyo: Author.

Ministry of Internal Affairs and Communications. (2016). Impact status of the 2011 Tohoku Earthquake and Tsunami as of March 1st 2016 [Tohoku chihou taiheiyouoki jishin no higai joukyou, heisei 28 nen 3 gatsu 1 nichi genzai]. Tokyo: Author.

Miyake, Y., Okamoto, Y. (2015). Mental health of university students. Japanese Journal of Psychosomatic Medicine, 55, 1360-1367.

Miyazaki, Y. (2018). Shinrin-yoku: The Japanese way of forest bathing for health and relaxation. London: Aster.

National Police Agency. (2010). Traffic Accidents in 2009 [Heisei 21-Nen Chuu no Koutsuujiko no Hassei Jyoukyou]. Tokyo: Author.

Neff, K. (2003). Self-compassion: an alternative conceptualization of a healthy attitude toward oneself. Self and Identity, 2, 85-101. 
Nishi, D., Ishikawa, H., \& Kawakami, N. (2019). Prevalence of mental disorders and mental health service use in Japan. Psychiatry and Clinical Neurosciences, 73(8), 458-465.

Patel, V., Saxena, S., Lund, C., Thornicroft, G., Baingana, F., Bolton, P., ... Herrman, H. (2018). The Lancet Commission on global mental health and sustainable development. The Lancet, 392(10157), 1553-1598.

Park, B. J., Tsunetsugu, Y., Lee, J., Kagawa, T., \& Miyazaki, Y. (2012). Effect of the forest environment on physiological relaxation-the results of field tests at 35 sites throughout Japan. Q. Li (Ed.), Forest medicine, Nova Science Publishers, Inc, New York (2012), pp. 55-65.

Peplau, L. A., \& Perlman, D. (Eds.). (1982). Loneliness: A sourcebook of current theory, research, and therapy. New York: Wiley.

Pritchard, A., Richardson, M., Sheffield, D., \& McEwan, K. (2019). The relationship between nature connectedness andeudaimonic well-being: A meta-analysis. Journal of Happiness Studies, 1-23.

Rajoo, K. S., Karam, D. S., Abdul Aziz, N. A. (2019). Developing an effective forest therapy program to manage academic stress in conservative societies: A multi-disciplinary approach. Urban Forestry \& Urban Greening 43, 126353.

Ratanasiripong, P., China, T., \& Toyama, S. (2018). Mental health and well-being of university students in Okinawa. Education Research International, 2018. https://doi.org/10.1155/2018/4231836

Richardson, T., Elliott, P., \& Roberts, R. (2017). Relationship between loneliness and mental health in students. Journal of Public Mental Health, 16(2), 48-54.

Ritchie, H., \& Roser, M. (2018). Mental health. Retrieved June 1, 2020, from https://ourworldindata.org/mental-health. 
Ryan, R. M., Weinstein, N., Bernstein, J., Brown, K. W., Mistretta, L., \& Gagné, M. (2010). Vitalizing effects of being outdoors and in nature. Journal of Environmental Psychology, 30, 159-168.

Shiiba, S. (2013). Wagakuni no mental health taisaku no genjou to kadai [Status and challenges for Japanese mental health policies]. Paper presented at the Labour Policy Forum, Tokyo, Japan. Retrieved from http://www.jil.go.jp/event/ro_forum/20130121/resume/shiiba.pdf

Stewart-Brown, S., Tennant, A., Tennant, R., Platt, S., Parkinson, J., \& Weich, S. (2009). Internal construct validity of the Warwick-Edinburgh mental well-being scale (WEMWBS): a Rasch analysis using data from the Scottish health education population survey. Health and Quality of Life Outcomes, 7, 15.

Uchida, C. (2010). Suicide among Japanese university students: From the resuls of a 21 year survey. A clue to prevent suicide among university students. Psychiatria et Neurologia Japonica, 112(6), 543-560.

Van Dam, N. T., Sheppard, S. C., Forsyth, J. P., \& Earleywine, M. (2011). Self-compassion is a better predictor than mindfulness of symptom severity and quality of life in mixed anxiety and depression. Journal of Anxiety Disorders, 25, 123-130.

Williams, F. (2016). This is your brain on nature. Retrieved August 10, 2020, from https://www.nationalgeographic.com/magazine/2016/01/call-to-wild/

World Health Organization (2017). Urban green space interventions and health: A review of impacts and effectiveness. Full report. Retrieved from: https://www.euro.who.int/en/health-topics/environment-and-health/urban-health/publi cations/2017/urban-green-space-interventions-and-health-a-review-of-impacts-and-eff ectiveness.-full-report-2017 
Yu, C., \& Hsieh, H. (2020). Beyond restorative benefits: Evaluating the effect of forest.therapy on creativity. Urban Forestry \& Urban Greening, 51, 126670.

Zessin, U., Dickhäuser, O., Garbade, S. (2015). The relationship between self-compassion and well-being: a meta-analysis. Applied Psychology, 7(3), 340-364. 